\title{
Pregnant Women's Perception before the Difficulties of Access to High-Risk Prenatal Care
}

Ana Maria Martins Pereira1, Daniela Gardano Bucharles Mont'Alverne ${ }^{2}$, Raimunda Magalhães da Silva ${ }^{3}$, Dafne Paiva Rodrigues ${ }^{4}$, Maria Albertina Rocha Diógenes ${ }^{5}$, Lia Maristela da Silva Jacob ${ }^{6}$, Herla Maria Furtado Jorge ${ }^{7}$, Maiza Claudia Vilela Hipólito ${ }^{8}$, Janaine Chiara Oliveira Moraes ${ }^{9}$

\section{Abstract}

Objective: To identify the pregnant women's perception before the finding of high-risk pregnancies and the difficulties of access to highrisk prenatal care.

Methodology: This is a descriptive and exploratory study with a qualitative approach, conducted with 15 pregnant women at high-risk prenatal care service of a public hospital in Fortaleza/Ceará.

Results: Pregnant women reported as difficulties the negligence on availability and assistance of high-risk prenatal service, lack of information about their disease, and the absence of a concrete link to reference and counter reference.

Conclusion: The need for a close look at all professionals working in health care services is emphasized, especially those working in primary care for the realization not only of early diagnosis but to charge those responsible for solving referred cases, fulfilling the principles of universality, comprehensiveness and equity.

\section{Keywords}

Prenatal Care; Health Systems; High-Risk Pregnancy; Access to Health Services; Nursing.

\section{Introduction}

Pregnancy is gradually taking over new dimensions and every day becomes disturbing and questioning to understand about this reality.
1 Master in Public Health. Professor at the Nursing Undergraduate Program, Faculty Earth Northeast. Assistance nurse at the Center of Normal Birth.

2 Doctor of Sciences in the area of Pneumology Concentration, University of São Paulo. Professor in Physiotherapy Course of the Federal University of Ceará.

3 Post-doctorate in Community Health. Professor of the University of Fortaleza (UNIFOR).

4 Doctor in Nursing from the Federal University of Ceará (UFC). Adjunct Professor of the Undergraduate Nursing Course and Postgraduate Program in Nursing and Health Clinical Care of the University of Ceará State (UECE).

5 Ph.D. in Nursing from the Federal University of Ceará. Adjunct Teacher I in Nursing Course, University of Fortaleza.

6 Master of Public Health, University of Fortaleza. Doctoral Student in Health Sciences from the Nursing School at the State University of Campinas.

$7 \mathrm{PhD}$ student of the Postgraduate Program in Obstetrics and Gynecology, State University of Campinas. Professor of the Undergraduate Nursing Course, University of Fortaleza, Fortaleza.

8 PhD student of the in Physical Education of the State University of Campinas. Professor at the Serviço Nacional de Aprendizagem Comercial.

9 Nurse. Master's Degree in Nursing. Federal University of Campina Grande (UFCG). Nursing Departmen.

Contact information:

Ana Maria Martins Pereira.

” aninhamartins_pereira@yahoo.com.br 
Despite being a physiological process inherent to the evolutionary cycle, it causes changes in the physical, psychological and social order in the woman, being essential to perform a qualified monitoring to prevent complications [1].

Even with all technological and scientific advances of recent decades in the field of women's health, when was possible for Brazil to reduce by $43 \%$ of its maternal deaths since the $90 \mathrm{~s}$, is still observed a high mortality rate from harmful complications during gestation-puerperal period, among which most part is the result of preventable problems [2]. The values of maternal mortality remain above the target set by the "Millennium Development Goals", raised by the World Health Organization (WHO), which aimed a reduction of 75\% until 2015 [3].

Studies show that the control of maternal/fetal morbidity and mortality is directly rooted in issues regarding the adequacy of care, access to health services promptly and the required level of complexity [4]. In this perspective, the prenatal is inserted, which has as purpose to receive the woman from the early stages, ensuring, at the end of pregnancy, the birth of a healthy child and ensuring maternal and neonatal welfare [5].

Adding to the problem, the various outcomes that influence the course of pregnancy, which should be highlighted, the social, economic, cultural, religious and conditions of life and work. In this sense, prenatal care glimpses the detection and treatment of maternal disease; monitoring the evolution of pregnancy by observing the pregnant woman's condition and evaluation of fetal development; diagnosis and treatment of pre-established clinical complications or aggravated by pregnancy; the recommendation of preventive measures for the health and preparation of pregnant women and family for childbirth and postpartum [6].

Prenatal care should be organized to meet the real needs of the entire population of pregnant women in their área, through the use of techni- cal and scientific knowledge and appropriate and available means and resources. Therefore, the effectuation of the comprehensiveness principle is essential, regarding the high-risk pregnant women care, seeing the diagnostic sensitivity of the basic level propose favorable referrals through the services network of the reference and counter reference system [5].

Before the presented and considering the magnitude that permeates the high-risk pregnancy, the development of this study is justified by the clear need to assess the barriers faced by pregnant women on the script of this prenatal high-risk care, and to glimpse the whole process with the range of complexity that surrounds it, not limiting it only to its biological aspect, extending the interventions that may be necessary to promote health and disease prevention. Thus, the conductive questions were: Which are the feelings of the pregnant women before the diagnosis of a high-risk pregnancy? Which are the difficulties experienced by pregnant women in their script to the specialized health services? Thus, this study aims to identify the perception of pregnant women before the finding of high-risk pregnancies and the difficulties of access to high-risk prenatal care.

\section{Method}

This is a descriptive and exploratory study with a qualitative approach and had the research focused on the high-risk prenatal clinic, General Cesar Cals Hospital (HGCC), located in the city of Fortalezal Ceará. Fifteen pregnant women participated in the study, who were performing prenatal care in the mentioned sector and had been referred by health units or other secondary care hospitals. Some participants were defined considering the criterion of theoretical saturation of data because it is understood that the questions placed to respondents and the research objectives in the search for new components that little appear, guide its finalization [7]. 
The following inclusion criteria were used for recruitment of research subjects: pregnant women aged greater than or equal to 18 years old, diagnosed with pregnancy complications and followedup in high-risk prenatal care. The low-risk pregnant women were excluded, those that in the outpatient care in the service was given merely for convenience and those that showed cognitive and verbal communication deficit.

From March to July 2014 the data collection was held through the visits to the hospital institution, by conducting semi-structured interviews, guided by a previously prepared script, consisting of closed questions about socio-demographic and obstetric data, such as age, gestation period, origin, marital status, educational level, profession, transport for displacement and religion, as well as guiding questions relevant to the selected theme.

After the clarification about the purpose of the study and its consent confirmed by signing the Informed Consent Form (ICF), pregnant women were invited to participate voluntarily, the interviews were recorded in MP4 device to favor the full transcript, which occurred on the same day of collection, thus avoiding the loss of the details of the speech and to remain anonymous, the respondents had their IDs replaced by names of flowers.

The data were analyzed supported in the content analysis proposed by Bardin [8] through the pre-analysis phases, where the speeches were transcribed and separated by proceeding to the initial reading thereof; exploitation of the material with comprehensive reading, and being possible to extract the core meaning and when defined the nuclei highlighted in the reports, these were cut without losing the context, obtaining the excerpts of the interviews that responded to the question9. Thus, emerged two themes: "Feelings assigned by pregnant women before a high-risk pregnancy" and "Difficulties reported by pregnant women accessing to high-risk prenatal care."
All ethical and legal principles of the research involving human beings were respected, according to which values the Resolution No. 466/12 of the National Health Council/Ministry of Health, and the work previously approved with opinion No. 625.818 [10].

\section{Results and Discussion}

The followings are the socio-demographic and obstetric data from participants, and then the categories that emerged from the performed analysis.

\section{Characterization of participants}

Fifteen pregnant women participated in the study, aged from 18 to 45 years old, with a gestation period ranging between 18 and 40 weeks. Of these, eight were from other cities such as Caucaial Ceará, Sobral/Ceará, Crato/Ceará, Itapipoca/Ceará, Caninde/Ceará, Maracanaú/Ceará, Boa Viagem/ Ceará and Rio de Janeiro/RJ, and seven came from the municipality of Fortaleza/Ceará. Concerning color, twelve women said they were brown and the other said that were white. Regarding marital status, seven participants were married, six lived in a consensual union, and two were single. It was noticed a family structure among twelve couples, and that stressed the importance of support from the partner/husband during pregnancy. The single, though they did not reside in the same home with the parents of their children, one of the women held an emotional bond with the partner, although living with their relatives because of economic circumstances; another participant reported having been abandoned by the child's father before knowing the existence of pregnancy, and currently was living with the family for whom she worked. In addition to the spouses, a pregnant woman reported cohabiting with other children, mother, sisters, mother-in-law, sister-in-law, uncles, cousins, mistress and friend. 
Regarding the educational level, there was a low educational level among the interviewees, wherein the sample, only three completed high school. Most, eight pregnant women, have not completed elementary education; two, the elementary school and two, incomplete high school. Education is one of the factors that helps pregnant women to understand the guidelines offered by health professionals, as well as the effectuation of prenatal care. The divergence is expressed by observing that despite the unfavorable conditions and family income ranging from one to two minimum wages, all women had at least six prenatal consultations in their coverage of health units, and adopting monitoring the high-risk clinic, faithfully.

Regarding the profession/occupation, it was found that three pregnant women were seamstresses; three were saleswomen; one farmer; two acted as merchants; one was a student, and five reported being homemakers or day laborers. Concerning religious practices, eleven are Catholic and only four members of the evangelical church.

Regarding the diseases diagnosed in the pregnancy participants: two cases of urinary tract infection, one didelphic uterus and hypertension, one lupus, one deep vein thrombosis and cerebrovascular accident, one hypothyroidism, five gestational diabetes, one twinning, one toxoplasmosis and two heart disease.

\section{Feelings assigned by pregnant women before a high-risk pregnancy}

Pregnancy causes physical, emotional and social events in the lives of women and their families. The expectations and concerns increases, predisposing them to the impairment of their health needs and complaints related to pregnancy and the meanings attributed to pregnancy can promote or interfere with self-care, in the family, social, economic and labor relations, as well as other pregnancies that follow. In this category, we investigated about the natural feelings of pregnant women at the time of diagnosis of a high-risk pregnancy and the meaning generated in their lives.

The trajectories about the findings of this new and unexpected situation related to pregnancy were expressed with a variety of feelings involving sadness, resignation, anger, fear, and insecurity, as shown in the following lines:

In fact because of the age I expected it was a high-risk pregnancy, I was more worried when I knew I was diabetic because I did not know, but about the high-risk pregnancy I did not feel terrify, I'm not usually worried about things, in these moments we have to stay calm and do what you have to do.

White Jasmine.

The growing rate of women postponing motherhood is due to changes resulting from greater female participation in the job market and longer professional training. The main maternal complications found in the age group above 35 years old are: gestational hypertension, gestational diabetes mellitus, higher frequency of operative deliveries, premature labor, placenta previa, premature rupture of membranes and multiple pregnancies [11].

Thus, late pregnancy requires from professionals, society and the family, a rigorous and continuous care. It is evident the need for guidance by health professionals by engagement of a multidisciplinary team, especially an adequate prenatal care and assistance during labor, childbirth, the postpartum period and the newborn, and may thus, minimize the deleterious effects of high maternal age on the woman and her baby [11].

Other reports show the pregnant women concerned about the health of both, mother/fetus. Prenatal is the time to support pregnant women, where women aspire security and information about the conduction of pregnancy, characterizing this space as propitious to learning, self-knowledge and information exchange [11]. 
It was hard because I was sad because it was the first, and I was already to be found, right, because I was born with it, a malformation (Delfo Uterus) and I always did transvaginal and never any doctor said nothing, always said everything was normal, it was difficult, they have already put in my head that I would not be able to take up to seven months, that I may lose up to five, I had the risk, I really had the risk, but thank God it is working until now.

Tulip.

I was afraid, you know, because of twins, so they direct me here, because there have no device, such things, to be examined, and so they direct me here.

Lavender.

Based on the exposed by Lavender interviewed, the presence of two or more fetuses in the uterine cavity defines twin pregnancy [4]. The incidence has increased in recent years, thanks to some predisposing factors, among the highest frequency and the best result of the procedures in assisted human reproduction and pregnancy in a more advanced age. Multiple pregnancies are associated with increased perinatal morbidity and mortality, mainly a result of increased number of premature neonates and low birth weight. Determine also a higher frequency of fetal malformations, and vascular changes and amount of amniotic fluid [4].

I was worried, you know, because I had no problem in other pregnancies, only at this one I had diabetes, I am still a little worried, you know, I had never made the diabetes examination, and when I started prenatal care in the unit, I did it and was positive.

Lotus.

The concern was observed with the evolution of pregnancy, the fear of losing the baby and anxiety were highlighted by many pregnant women due to several causes. The speech of the White Rose showed up these feelings generated by the evolution of her high-risk pregnancy and also by ignorance of the real diagnosis or her disease associated with this pregnancy. These reports lead to reflect about the bureaucratic model of care, where the professional overloads on secondary tasks, relegating the assistance role, a fact that brings undoubted losses especially in care for pregnant women.

I did not even know what it was, you know, the doctor said that my thyroid was changed, and I said what this thyroid is, then she said she would refer me to Cesar Cals Hospital, and I cried a lot because when she said high-risk, we feel desperate.

White Rose.

It was noticed that the greatest anguish of pregnant women is related to the lack of information given to them, especially by the medical professionals. To know the reason that led them to a highrisk clinic should be a priority for the professional who is forwarding or referencing. In this context, the quality of prenatal care has been evaluated by the number of visits and gestational age of entry into the health service [12].

Aside from these aspects, adds that women attribute meanings to the reproductive process, to the faced needs and complications, to the causes of these, to the actions and resources of health services and other, and that culminate influencing all their health process, their collaboration in self-care, and may also constitute for increased vulnerability [13].

\section{Difficulties reported by pregnant women to access the high-risk prenatal care}

The construction of the category about the difficulties to access the high-risk prenatal care contributes to many concerns, becoming something expected by the researcher who decides to find the study barriers. The negligence on the availability and assistance of prenatal service was a worrying fact, and also the absence of a concrete link between the 
system of reference and conter reference, primordial guidelines of the Unified Health System (SUS) and Primary Care in Brazil. The citations below unveil the problem:

The unit is only mercy, when I found out I had 02 months, I've been five times in the unit to get an appointment, I had to cry, make a drama to the Nurse that serves pregnant. She had dengue, she is absent, so when I came here, I did not take my card, he wondered, the balance does not work, she only heard me, to make an electro and I went to a private because I had to wait 60 days.

Orchid.

The delay to be a high-risk prenatal and must be forwarded by the unit and stand in the queue, because if you do not know a person in the hospital, it is difficult, because the Nurse is a doctor friend, if not I would still be awaiting.

Daisy.

In a study performed with eleven nurses working in prenatal and postpartum care in Family Basic Health Units (FBHU), it was observed that, when sent to high-risk care, due to Hypertensive Disease Specific of Pregnancy (HDSP), pre-eclampsia, diabetes, fetal distress or other pathologies, professionals end up losing the continuity of care of pregnant women, which unlink the prenatal care and delivery, leading women to wander in search of vacancies in hospitals [14].

This reality resembles the interviewed pregnant women, since, whether assisted at high-risk of a reference institution clinic, it is clear that there is no theory connection with practice, and that constantly, patients entering in labor in days when there is no vacancy in the tertiary hospital, are transferred to the secondary level hospitals, which often do not have adequate supplies of the pregnant woman needs, in case of possible complications during that period.
The monitoring of prenatal care has fundamental importance since it presupposes dynamic assessment of risk factors and readiness to identify problems to be able to act in situations where the binomial take risks, depending on the found problem, to prevent an unfavorable result3. Moreover, the impasses in high-risk prenatal care also extend to the shortage of human and material resources to achieve equally demand. Participants demonstrate in their speeches (White Rose, Lavender, and Orchid) the difficulty in obtaining basic tests during pregnancy assistance, such as ultrasound, in addition to the denial of another principle of public health, the access universality.

The difficulty was only on the ultrasound, I stayed two months and could not, I did particular, so I brought it and showed that was the only complicattion.

White Rose.

No, the difficulty I had was just that I had to make a registration to be attended here, but because I have a cousin who is a doctor in Cesar Cals, and he helped me, as was about six months I was waiting to have a vague and was not showing up, so I talked to him and he helped me.

Lavender.

The Doctor sent me to the health department, they asked me to wait, and they will call me to say when had vague, so I was praying for a vague, the examinations spend 03-04 months to be ready.

Orchid.

According to the Ministry of Health (MOH), the promotion of safe motherhood is a collective responsibility commitment of all health professionals, who should strive for humanization of prenatal care, by paying particular attention to the a small portion of pregnant women who are carriers of diseases that may worsen during pregnancy or 
present problems that may have been triggered in this period [3].

The latest Policy elaborated by the Ministry of Health reaffirms all the others already published in attention to women's health, in which we highlight the Stork Network, that is a strategy to implement a caring web to ensure women the right to reproductive planning and humanized attention to pregnancy, childbirth and the postpartum period, and guarantee children the right to birth free of damage and the healthy growth and development [15].

The Stork Network program provides the strengthening of obstetric hospital environment of high-risk, the progressive increase in the number of SUS beds and professionals qualification. This also addresses in the course of its text, the need for performing the minimum of six prenatal consultations and clinical and laboratory examinations to primary health care; the advance information of the women about the probable place of their birth; receiving transportation and taxi vouchers to displacement to the health unit and maternity [15]. However, in practice, what you see is a still fail policy, not applicable to reality experienced by pregnant women at high-risk monitoring, as the following speeches:

The Echocardiogram that so far is on the waiting list, I did not, is three months without it at the Hospital Cesar Cals.

Daisy.

"In attendance was the exams, because at the moment we do not have an income to pay for the examinations that the doctor asked, the hospital is not taking these exams, the I could pay the Basic Unit. I had great difficulty in June, I went through the system, and she got a place for me immediately, I could have the consultation of the month, I spent a month to get it.

Purple Rose
Among the women who had trouble getting a job, there was one that get it expeditiously because she came referenced from a hematology service and not from a Basic Unit as most of them, so she did not have to wander because the transfer was made from doctor to doctor. However, the ultrasound examinations remain ascending. This scene is very common in the practice related to health care, and some references do not happen by formal procedures, equity in this sense is unset. For those who get the job precociously, it is undoubtedly very important, but for those who have to wait months to get, will certainly be very distressing.

\section{Conclusion}

By proposing to study the feelings of high-risk pregnant women who sought hospital care, it can begin from a place of knowledge and (pre) concepts to another which is possible to see that the roads are much more complex and unique, at a certain time in this walk. There are changes on the trails and shortcuts.

The study found that pregnant women know little about their condition. This lack of information is often reflected in an unfavorable outcome for the mother and the fetus, and therefore, the symptoms that require self-care can be trivialized. Moreover, it was noted that, given the obstetric practice, some outstanding goals in Network Stork Policy have not left the drawing board. It is true that many changes are happening, even if slowly, with great encouragement to the humanization of delivery and investments in better service conditions. However, the lack of structure, as well as professionals prepared to attend the mother in full, prevents the performance of the proposed paradigms and implies the pilgrimage of pregnant women for care.

It was observed that even pregnant women considered at high-risk have priority access to health services, evidenced by the long line waiting for a 
vacancy in specialized prenatal care, the delay and shortage of resources as basic blood tests and ultrasound and breaking the link with the reference unit.

Thus, we emphasize the need for a close look at all professionals working in health care services, especially those working in primary care, for the realization not only of early diagnosis but to ask those responsible for the solving of referred cases, fulfilling the universality, comprehensiveness, and equity principles. To make that health policies and programs for women happen in a more practical way, it is undoubtedly one of the biggest challenges for professionals, managers, society and the very realization of the SUS.

It is not expected that the results of this assessment can translate a decision-making in the service, but that the produced information could contribute to review the weaknesses of behaviors and improve the quality of care for risk pregnancies.

\section{References}

1. Martinelli KG, Santos Neto, Gama SGN, Oliveira AE. Adequação do processo da assistência pré-natal segundo os critérios do Programa de Humanização do Pré-natal e Nascimento e Rede Cegonha. Rev. Bras. Ginecol. Obstet. 2014; 36(2):56-64.

2. Szwarcwald CL, Escalante JJC, Neto DLR, Junior PRBS, Victora CG. Estimação da razão da mortalidade materna no Brasil, 2008-2001 Estimação da razão da mortalidade materna no Brasil, 2008-2001. Cad. Saúde Pública, Rio de Janeiro. 2014; 30:71-83.

3. Brasil. Objetivos de Desenvolvimento do Milênio: Relatório Nacional de Acompanhamento/Coordenação: Instituto de Pesquisa Econômica Aplicada e Secretaria de Planejamento e Investimentos Estratégicos; supervisão: Grupo Técnico para o acompanhamento dos ODM. Brasília: Ipea: MP, SPI, 2014.

4. Domingues RMSM, Viellas EF, Dias MAB, Torres JA, ThemeFilha MM, Gama SGN, et al. Adequação da assistência pré-natal segundo as características maternas no Brasil. Rev Panam Salud Publica. 2015; 37(3):140-7.

5. Peixoto CR, Freitas LV, Teles LMR, Campos FC, Paula PF, Damasceno AKC. O pré-natal na atenção primária: o ponto de partida para reorganização da assistência obstétrica. Rev. Enferm. UERJ. Rio de Janeiro, 2011 abr/jun; 19(2):286-91.

6. Caldas DB, Silva ALR, Böing E, Crepaldi MA, Custódio ZAO. Atendimento psicológico no pré-natal de alto-risco: a construção de um serviço. Psicologia Hospitalar, 2013, 11 (1), 66-87.
7. Fontanella BJB et al. Amostragem em pesquisas qualitativas: proposta de procedimentos para constatar saturação teórica. Cad. Saúde Pública, Rio de Janeiro. 2011, 27(2):389-394.

8. Bardin L. Análise de conteúdo. São Paulo: Edições 70, 2011.5.

9. Minayo, MCS. O desafio do conhecimento: pesquisa qualitativa em saúde. 13. ed., São Paulo: Hucitec, 2013.

10. Brasil. Diretrizes e normas regulamentadoras de pesquisas em seres humanos. Resolução n.466 de 12 de dezembro de 2012. Ministério da Saúde/ Conselho Nacional de Saúde. Brasília, 2012b.

11. Gonçalves ZR, Monteiro DLM. Complicações maternas em gestantes com idade avançada. Revista Femina. 2012; 40(5).

12. Anversa ETR, Bastos GA, Nunes LN, Dal PTS. Qualidade do processo da assistência pré-natal: unidades básicas de saúde e unidades de Estratégia Saúde da Família em município no Sul do Brasil. Cad. Saúde Pública [online]. 2012; 28(4):789-800.

13. Oliveira DC, Mandu ENT. Mulheres com gravidez de maior risco: vivências e percepções de necessidades e cuidado. Esc. Anna Nery [online]. 2015; 19(1):93-101.

14. Guerreiro EM, Rodrigues DP, Silveira MA, Lucena NBF. O cuidado pré-natal na atenção básica de saúde sob o olhar de gestantes e enfermeiros. Reme - Rev. Min. Enferm. 2012; 6(3): 315-323.

15. Brasil. Ministério da Saúde (MS). Portaria $n^{\circ}$ 1.459/ GM/MS, de 24 de junho de 2011, que institui, no âmbito do Sistema Único de Saúde (SUS), a Rede Cegonha. Diário Oficial da União 2011; 25 jun.

\section{Publish in International Archives of Medicine}

International Archives of Medicine is an open access journal publishing articles encompassing all aspects of medical science and clinical practice. IAM is considered a megajournal with independent sections on all areas of medicine. IAM is a really international journal with authors and board members from all around the world. The journal is widely indexed and classified Q1 in category Medicine. 